\title{
Real estate evaluation model based on the method of least squares
}

\author{
Jacek Zyga \\ Lublin University of Technology, Faculty of Building and Architecture, \\ Department of Geotechnics, e-mail: j.zyga@pollub.pl
}

\begin{abstract}
New way of estimating of real estate market value, based on the least squares method, was presented in the article. Testing of applying same ideas of statistical approach into the routine way of appraisal of particular immovable estate shown that the proposed way of valuation is under some circumstances as good as the "in-pairs comparing" method, the most universal one from among methods of comparing approach. Although "in-pairs comparing" method is regarded as the most accurate one, conducted experiments clearly shown its own, inherent limits, that radically restrict the field of its use.
\end{abstract}

Key words: real estate valuation, real estate pricing, in pairs comparison method, the method of least squares.

\section{Introduction}

One of the most common and practical methods in the pricing of real estates is referring, in valuing estimations, to evaluations made by other participants of the local market. In the Polish law this method is described as the comparative approach. It is one of the four approaches which are legally recognized. The remaining three include:

- income capitalization approach,

- cost-based approach,

- mixed approach.

The comparative, income or mixed approaches are used to estimate the market value of a real estate. The cost-based approach is intended to estimate the reproduction value of real estates.

The income capitalization approach consists in evaluating of a real estate assuming that the purchaser of such an estate will pay the price which will depend on the forecast income to be obtained from the real estate sale. Real estates that bring or are likely to bring a return should be appraised using that approach.

The cost-based approach consists in evaluating of a real estate assuming that such value reflects the cost of its reproduction decreased by the physical depreciation of such a real estate. In that approach the cost of land purchase and the cost of reproduction of its parts are specified individually.

The mixed approach is a combination of the ideas inherent in the three main approaches. Although it is the quintessence of appraisal methods used in the real 
state developing market (and seems to be a highly professional way of appraisal), it is not recognized as a fully autonomous approach. Article 152 paragraph 3 of the Polish law on real estates economy ("Ustawa o gospodarce nieruchomościami") says that the mixed approach is intended to be used in a situation when existing market conditions do not allow the use of the income or comparative approaches.

As it was described above, the comparative approach consists in the estimation of a real estate market value, assuming that such a value meets the prices which have been obtained in the sales of similar real estates. Such prices are obviously subject to corrections due to the features differing similar real estates from the evaluated one, and due to price changes in time. A necessary condition to use the comparative approach is the knowledge of prices of similar real estates and features of such estates as well as the features which have an effect on the level of transactional prices.

Focusing on the comparative approach in this article we will omit the analysis of detailed descriptions of pricing methods classified as income, cost and mixed approaches and concentrate exclusively on the methods of the comparative approach. The general procedures of comparing real estates are defined in the Statutory Instrument Resolution of the Council of Ministers regarding the pricing of real estates and preparing of evaluation report from 2004-09-21 (Journal of Laws 2004 No 207, item 2109), where the procedures were categorized into the three methods of pricing:

- in -pair comparison method,

- average price correcting method,

- methods of market statistical analysis.

Contrary to an intuitive expectation, the methods above have not been listed according to the number of records that are used in the appraising of objects. The expected order is violated by the average price correcting method, practically based on two real estates sold for the lowest and highest prices (from the assumption) and logically connected evaluations of market features. In the face of wide criticism of this method it will also remain beyond the scope of this article.

Consequently, the in pairs comparison method and methods of market statistical analysis (or rather one of many, possible to define, methods using statistics as a tool) shall be considered as the subject of the article. Someone could challenge this list because of contradictory features of the two compared methods. However, as one can see in the next passage both of the compared methods can give convergent results.

\section{The general form of the value model in the in pairs comparison method}

The model of the unit value of the priced real estate, whose framework record is included in the Interpretative Note N1 of Polish Federation of Valuers Associations (until recently in the standard of PFVA no III.7 ) can be defined with the following formula:

$$
W^{P R E}=\frac{1}{n} \sum_{i=1}^{n}\left(P S_{i}+\Delta P S \sum_{j=1}^{m} \frac{M_{j}^{P R E}-M_{i, j}^{S}}{M_{j}^{\max }-M_{j}^{\min }} \cdot w_{i, j}\right)
$$


where: $W^{P R E}$ - the value of the comparative unit of priced real estate, $P S$ - the price of the comparative unit of sold real estate, (after the correction to allow for changing of prices in time), $\triangle P S$ - the range of prices of the comparative unit of sold real estates in the local market (after the corrections due to their changes in time), $M^{P R E}$ - the mark of the priced property within the $j$-th market feature* $M^{s}{ }_{i j}$ - the mark of $i$-th sold property accepted for in pairs comparisons within the $j$-th market feature*, $M^{\text {max }}$ - the maximum mark of real estates in the market test within the $j$-th market feature* $M^{\min }$ - the minimum mark of real estates in the market test within the $j$-th market feature ${ }^{*}, w_{i, j}$ - the weight of the market feature (the fractional share of the market feature in the range of prices in the market test), $n$ - the number of transactions, $m$ - the number of market features.

* / A market feature means a single feature or a group of features that can affect the changes of market prices of real estates and whose influence can be recognized.

The above formula presents the simplest way of finding the most probable solution, but the formula of the general arithmetical mean with the use of coefficients of partial estimations significance is also acceptable. Only to simplify the reasoning, however, it is advisable to take the formula (1) as sufficient for inferring conclusions on the effect of particular arguments on the final result of their function, i.e. estimated market value. The marks of market features of real estates (the priced one and sold ones as well) are a very subjective factors in the whole process of pricing. These marks can be expressed in numbers or as seriate ranks (in that case lengths of intervals $I$ between each mark are important).

$$
\frac{M_{j}^{P R E}-M_{i, j}^{S}}{M_{j}^{\max }-M_{j}^{\min }}=\frac{I_{j}^{S, P R E}}{I_{j}^{\min , \max }}
$$

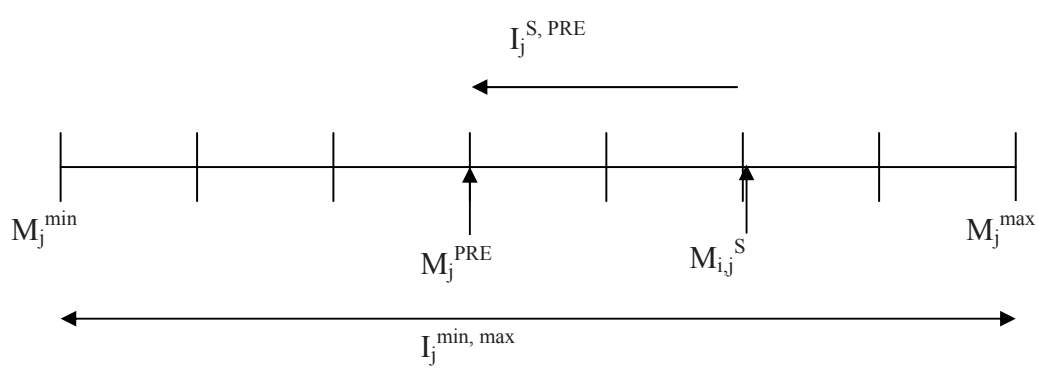

Fig. 1. The schema of estimation of the marks proportion coefficient for a particular $j$-th market feature in comparisons of the priced real estate and $i$-th sold, comparative real estate.

\section{The form of the alternative model}

The alternative model of the real estate market value uses a well-known technology which consists of the method of least squares combined with the rule of the differential method.

The starting point is the additive model of the transactional price assuming that the final price of a real estate is the result of financial effects of different factors. In the presented case market features with their marks are regarded as the factors mentioned above. 


$$
P S_{i}=\sum_{j=1}^{m}\left(w_{j} \cdot \frac{M_{i, j}^{S}-M_{j}^{\min }}{M_{j}^{\max }-M_{j}^{\min }} \cdot X_{j}\right)+P S^{\min }+v_{j}
$$

where: $P S_{j}$ - the price of comparative unit of the $i$-th sold real estate (after the correction by time-dependent factor), $P S^{\text {min }}$ - the lowest price in the set of comparative unit prices of sold real estates on the local market (after the correction by time dependent factor), $M^{s}{ }_{i j}$ - the mark (rank) of the $i$-th sold real estate within the range of $j$-th market feature, $M^{\max }{ }_{j}$ - the maximum mark (rank) of the real estate in the market test within the $i$-th market feature, $M^{,{ }^{\text {min }}}$ - the minimum mark (rank) of the real estate in the market test within the $i$-th market feature, $w_{j}$ - the weight of $j$-th market feature expressed as a fraction, $m$ - the number of market features, $X_{j}-$ the maximum financial effect of $i$-th market feature on the price of a comparative unit of a sold real estate, $v_{j}$ - the stochastic component (residual).

In the face of the fact that the influence $\mathrm{X}$ of a market feature on the price of a comparative unit of a real estate is a parameter that structurally plays the role of an independent variable, it can be replaced with another variable that aggregates some elements of the formula (2). This action appears to be admissible because other elements of formula (2) such as $w$ weights of particular market features or intervals $I_{j}^{\min , \max }=M_{j}^{\max }-M_{j}^{\min }$ of extreme ranks of each feature remain constant under the circumstances of a local real estate market.

Introduction of the new variable:

$$
Y_{j}=w_{j} \cdot \frac{X_{j}}{M_{j}^{\max }-M_{j}^{\min }}
$$

redefines the model of the transactional price to the form:

$$
P S_{i}=\sum_{j=1}^{m}\left(\left(M_{i, j}^{S}-M_{j}^{\min }\right) \cdot Y_{j}\right)+P S^{\min }+v_{i}
$$

or alternatively:

$$
P S_{i}=\sum_{j=1}^{m}\left(I_{i, j}^{\min , S} \cdot Y_{i}\right)+P S^{\min }+v_{i}
$$

where:

$$
I_{j}^{\min , S}=M_{j}^{S}-M_{j}^{\min }
$$

When $n$ comparative unit prices (corrected by the time-dependent factor) and related ranks of real estates within the range of $\boldsymbol{m}$ selected market features are collected, then the system of $\boldsymbol{n}$ equations with $\boldsymbol{m}$ variables can be set.

$$
\begin{aligned}
& P S_{1}=\sum_{j=1}^{m}\left(I_{1, j}^{\min , S} \cdot Y_{j}\right)+P S^{\min }+v_{1} \\
& P S_{2}=\sum_{j=1}^{m}\left(I_{2, j}^{\min , S} \cdot Y_{j}\right)+P S^{\min }+v_{2}
\end{aligned}
$$




$$
P S_{n}=\sum_{j=1}^{m}\left(I_{n, j}^{\min , S} \cdot Y_{j}\right)+P S^{\min }+v_{n}
$$

In the matrix recording the system (5) can be represented as:

$$
P S-P S^{\min }=I \cdot Y+v
$$

where: $P S$ - $\mathrm{n}$ - element vector of comparative unit prices of sold real estates (corrected as mentioned above), $P S^{\text {min }}-\mathrm{n}$ - element vector composed of elements equal to the lowest price in the set of comparative unit prices of sold real estates on the local market (corrected as mentioned above), $I$ - the matrix of the model coefficients containing intervals between the ranks of sold real estates and minimum ranks within the range of each market feature, $Y-\mathrm{m}$ - element vector of aggregated variables, $v-\mathrm{m}$ - element vector of residuals.

The solution of the system of equations is the estimation of variable $\hat{Y}$ as shown below:

$$
\hat{Y}=\left(I^{T} I\right)^{-1} I^{T}\left(P S-P S^{\min }\right)
$$

Putting $\hat{Y}$ into the form (6) leads to the estimation of the unit market value of the object:

$$
V^{P R E}=\sum_{i=1}^{m}\left(\left(M_{i}^{P R E}-M_{i}^{\min }\right) \cdot \hat{Y}_{i}\right)+P S^{\min }
$$

The symbol $\hat{Y}_{i}$ in the form (8) means $i$-th element of the resulting vector $\hat{Y}$.

\section{The numerical example}

The mathematical check of the proposed way of the real estates valuation was conducted on the real data, i.e. a set of flats in the old buildings situated in a district of Warsaw, in 2009. The list of gathered records is shown in table no 1 as follows:

Table 1. The data set describing transactions in the local market of flats in the old buildings.

\begin{tabular}{cccc}
\hline $\begin{array}{c}\text { The transactional } \\
\text { unit price } \\
\text { PLN / m }{ }^{2}\end{array}$ & $\begin{array}{c}\text { The mark of } \\
\text { evaluation (rank) } \\
\text { of the building } \\
\text { technical conditions }\end{array}$ & $\begin{array}{c}\text { The mark of } \\
\text { evaluation (rank) } \\
\text { of the building type }\end{array}$ & $\begin{array}{c}\text { The mark of } \\
\text { evaluation (rank) } \\
\text { of the flat location } \\
\text { on a storey }\end{array}$ \\
\hline 29225,82 & 3 & 2,5 & 3 \\
12819,10 & 3 & 2 & 2 \\
47721,17 & 3 & 3 & 3 \\
47721,20 & 3 & 3 & 2 \\
38616,61 & 4 & 3 & 2 \\
41953,03 & 4 & 2 & 3 \\
41435,09 & 4 & 2 & 2 \\
\hline
\end{tabular}

All the remaining marks (e.g. available utilities, car accessibility, the type of land ownership) were omitted due to the invariability of their marks in the group. The weight factors of essential market features were estimated using the analysis of correlation of relative increases of transactional prices and changes of marks (ranks) 
of real estates of respective transactions, expressed in numbers. The figures of estimated factors are as follows:

Table 2. Market features and their weight factors.

\begin{tabular}{ccc}
\hline $\begin{array}{c}\text { The mark of evaluation (rank) } \\
\text { of the building technical } \\
\text { condition }\end{array}$ & $\begin{array}{c}\text { The mark of evaluation (rank) } \\
\text { of the building type }\end{array}$ & $\begin{array}{c}\text { The mark of evaluation (rank) } \\
\text { of the flat location of on a } \\
\text { storey }\end{array}$ \\
\hline 0,31521 & 0,59084 & 0,09395 \\
\hline
\end{tabular}

For several different variants of sets of market features marks, several simultaneous experiments were conducted:

A - estimations based on formula (1), applying external expertise on real estates similarity, entirely consistent with the legal requirements and in accordance with the Polish standards of valuation,

B - estimations based on formula (1), without searching for the most similar real estates (the estimations using all accessible transaction data),

$\mathrm{C}$ - estimations based on alternative stochastic statistical model (2-8) using all available transaction data.

The calculations were performed by means of Mathcad 6.0 software. The results of estimations are shown in Table no 3:

Table 3. The results of three variants of estimation of unit market value of objective flats and evaluation of mutual proportions of the results.

\begin{tabular}{|c|c|c|c|c|c|c|c|c|}
\hline \multicolumn{3}{|c|}{$\begin{array}{l}\text { Applied sets marks of market } \\
\text { features }\end{array}$} & \multicolumn{3}{|c|}{$\begin{array}{l}\text { Results of estimation of unit } \\
\text { market value of objective flats } \\
{\left[\text { PLN } / \mathrm{m}^{2} \text { p.u.] }\right.}\end{array}$} & \multicolumn{3}{|c|}{$\begin{array}{l}\text { Mutual proportions of esti- } \\
\text { mation results }\end{array}$} \\
\hline $\begin{array}{l}\text { The mark } \\
\text { of evalua- } \\
\text { tion (rank) } \\
\text { of the } \\
\text { building } \\
\text { technical } \\
\text { condition }\end{array}$ & $\begin{array}{l}\text { The mark } \\
\text { of evalua- } \\
\text { tion (rank) } \\
\text { of the } \\
\text { building } \\
\text { type }\end{array}$ & $\begin{array}{l}\text { The mark } \\
\text { of evalua- } \\
\text { tion (rank) } \\
\text { of the flat } \\
\text { location of } \\
\text { on a storey }\end{array}$ & $\begin{array}{c}\text { variant } \\
\text { A }\end{array}$ & $\begin{array}{c}\text { variant } \\
\text { B }\end{array}$ & $\begin{array}{c}\text { variant } \\
\mathrm{C}\end{array}$ & $\mathrm{B} / \mathrm{A}$ & $\mathrm{C} / \mathrm{A}$ & $\mathrm{C} / \mathrm{B}$ \\
\hline 2 & 1 & 1 & -15058 & -14263 & -36430 & 0,95 & 2,42 & 2,55 \\
\hline 2 & 1 & 2 & -11779 & -10984 & -26334 & 0,93 & 2,24 & 2,40 \\
\hline 2 & 1 & 3 & -8500 & -7704 & -16238 & 0,91 & 1,91 & 2,11 \\
\hline 2 & 1 & 4 & -5221 & -4425 & -6142 & 0,85 & 1,18 & 1,39 \\
\hline 2 & 2 & 1 & 5563 & 6359 & -14426 & 1,14 & $-2,59$ & $-2,27$ \\
\hline 2 & 2 & 2 & 8842 & 9638 & -4330 & 1,09 & $-0,49$ & $-0,45$ \\
\hline 2 & 2 & 3 & 12122 & 12917 & 5765 & 1,07 & 0,48 & 0,45 \\
\hline 2 & 2 & 4 & 15401 & 16196 & 15862 & 1,05 & 1,03 & 0,98 \\
\hline 2 & 3 & 1 & 26185 & 26980 & 7577 & 1,03 & 0,29 & 0,28 \\
\hline 2 & 3 & 2 & 29464 & 30259 & 17673 & 1,03 & 0,60 & 0,58 \\
\hline 2 & 3 & 3 & 32743 & 33539 & 27769 & 1,02 & 0,85 & 0,83 \\
\hline 2 & 3 & 4 & 36022 & 36818 & 37865 & 1,02 & 1,05 & 1,03 \\
\hline 2 & 4 & 1 & 46806 & 47602 & 29581 & 1,02 & 0,63 & 0,62 \\
\hline 2 & 4 & 2 & 50086 & 50881 & 39677 & 1,02 & 0,79 & 0,78 \\
\hline 2 & 4 & 3 & 53365 & 54160 & 49773 & 1,01 & 0,93 & 0,92 \\
\hline 2 & 4 & 4 & 56644 & 57439 & 59869 & 1,01 & 1,06 & 1,04 \\
\hline 3 & 1 & 1 & -4057 & -3261 & -19281 & 0,80 & 4,75 & 5,91 \\
\hline 3 & 1 & 2 & -778 & 17 & -518 & $-0,02$ & 0,67 & $-30,47$ \\
\hline 3 & 1 & 3 & 2501 & 3297 & 911 & 1,32 & 0,36 & 0,28 \\
\hline
\end{tabular}




\begin{tabular}{|c|c|c|c|c|c|c|c|c|}
\hline 3 & 1 & 4 & 5780 & 6576 & 11007 & 1,14 & 1,90 & 1,67 \\
\hline 3 & 2 & 1 & 16565 & 17360 & 2723 & 1,05 & 0,16 & 0,16 \\
\hline 3 & 2 & 2 & 19844 & 20639 & 12819 & 1,04 & 0,65 & 0,62 \\
\hline 3 & 2 & 3 & 23120 & 23918 & 22915 & 1,03 & 0,99 & 0,96 \\
\hline 3 & 2 & 4 & 26402 & 27198 & 33011 & 1,03 & 1,25 & 1,21 \\
\hline 3 & 3 & 1 & 37186 & 37982 & 24727 & 1,02 & 0,66 & 0,65 \\
\hline 3 & 3 & 2 & 40465 & 41261 & 34823 & 1,02 & 0,86 & 0,84 \\
\hline 3 & 3 & 3 & 43745 & 44540 & 44919 & 1,02 & 1,03 & 1,01 \\
\hline 3 & 3 & 4 & 47024 & 47819 & 55015 & 1,02 & 1,17 & 1,15 \\
\hline 3 & 4 & 1 & 57808 & 58603 & 46730 & 1,01 & 0,81 & 0,80 \\
\hline 3 & 4 & 2 & 61087 & 61882 & 59826 & 1,01 & 0,98 & 0,97 \\
\hline 3 & 4 & 3 & 64366 & 65162 & 66922 & 1,01 & 1,04 & 1,03 \\
\hline 3 & 4 & 4 & 67645 & 68441 & 77018 & 1,01 & 1,14 & 1,13 \\
\hline 4 & 1 & 1 & 6944 & 7740 & -2131 & 1,11 & $-0,31$ & $-0,28$ \\
\hline 4 & 1 & 2 & 10224 & 11019 & 7965 & 1,08 & 0,78 & 0,72 \\
\hline 4 & 1 & 3 & 13503 & 14298 & 18061 & 1,06 & 1,34 & 1,26 \\
\hline 4 & 1 & 4 & 16782 & 17577 & 28157 & 1,05 & 1,68 & 1,60 \\
\hline 4 & 2 & 1 & 27566 & 28361 & 19872 & 1,03 & 0,72 & 0,70 \\
\hline 4 & 2 & 2 & 30845 & 31641 & 29968 & 1,03 & 0,97 & 0,95 \\
\hline 4 & 2 & 3 & 34124 & 34920 & 40064 & 1,02 & 1,17 & 1,15 \\
\hline 4 & 2 & 4 & 37404 & 38199 & 50160 & 1,02 & 1,34 & 1,31 \\
\hline 4 & 3 & 1 & 48187 & 48983 & 41876 & 1,02 & 0,87 & 0,85 \\
\hline 4 & 3 & 2 & 51467 & 52262 & 51972 & 1,02 & 1,01 & 0,99 \\
\hline 4 & 3 & 3 & 54746 & 55541 & 62068 & 1,01 & 1,13 & 1,12 \\
\hline 4 & 3 & 4 & 58025 & 58821 & 72164 & 1,01 & 1,24 & 1,23 \\
\hline 4 & 4 & 1 & 68809 & 69605 & 63880 & 1,01 & 0,93 & 0,92 \\
\hline 4 & 4 & 2 & 72088 & 72884 & 73976 & 1,01 & 1,03 & 1,01 \\
\hline 4 & 4 & 3 & 75367 & 76163 & 84072 & 1,01 & 1,12 & 1,10 \\
\hline 4 & 4 & 4 & 78647 & 79442 & 94168 & 1,01 & 1,20 & 1,19 \\
\hline 5 & 1 & 1 & 17946 & 18741 & 15018 & 1,04 & 0,84 & 0,80 \\
\hline 5 & 1 & 2 & 21225 & 22020 & 25114 & 1,04 & 1,18 & 1,14 \\
\hline 5 & 1 & 3 & 24504 & 25300 & 35210 & 1,03 & 1,44 & 1,39 \\
\hline 5 & 1 & 4 & 27783 & 28579 & 45306 & 1,03 & 1,63 & 1,59 \\
\hline 5 & 2 & 1 & 38567 & 39363 & 37022 & 1,02 & 0,96 & 0,94 \\
\hline 5 & 2 & 2 & 41846 & 42642 & 47118 & 1,02 & 1,13 & 1,10 \\
\hline 5 & 2 & 3 & 45126 & 45921 & 57214 & 1,02 & 1,27 & 1,25 \\
\hline 5 & 2 & 4 & 48405 & 49200 & 67310 & 1,02 & 1,39 & 1,37 \\
\hline 5 & 3 & 1 & 59189 & 49984 & 59025 & 0,84 & 1,00 & 1,18 \\
\hline 5 & 3 & 2 & 62468 & 63264 & 69121 & 1,01 & 1,11 & 1,09 \\
\hline 5 & 3 & 3 & 65747 & 66543 & 79217 & 1,01 & 1,20 & 1,19 \\
\hline 5 & 3 & 4 & 69026 & 69822 & 89313 & 1,01 & 1,29 & 1,28 \\
\hline 5 & 4 & 1 & 79810 & 80606 & 81029 & 1,01 & 1,02 & 1,01 \\
\hline 5 & 4 & 2 & 83090 & 83885 & 91125 & 1,01 & 1,10 & 1,09 \\
\hline 5 & 4 & 3 & 86369 & 87164 & 10122 & 1,01 & 0,12 & 0,12 \\
\hline 5 & 4 & 4 & 89648 & 90443 & 11132 & 1,01 & 0,12 & 0,12 \\
\hline
\end{tabular}

Designedly applied sets of market feature marks, transcending the range of marks, defined by the local flat market circumstances, give the opportunity of rating both the reliability of the "in pairs comparison" method and also the appropriateness of the results received when using the alternative mathematical model.

\section{Conclusions}

The foremost conclusion arising from the experiment presented above is a statement that "in pairs comparison" method is not itself entirely resistant to 
adverse conditions emerging in the cases of extrapolation (when some transcend the range of marks defined by the local real estate market circumstances). In extreme cases, extrapolation of prices as a tool of calculation, as foreseen by the creators of the method and admitted by the law, can give wrong, unacceptable results of valuation, especially when the mark of the most important market feature of the objective real estate happens to transcend the range ordered local market conditions. However, the algorithm used in experiment A works properly as long as its calculations are based on interpolation rules. In other words, the "in pairs comparison" method algorithm is appropriate for the appraisal of real estates described in several market feature scales as "not better than the best" and "not worse than the worst'.

The analysis of the column containing proportions of the results of experiments $\mathrm{C}$ and $\mathrm{A}$ shows that the alternative mathematical model described by formulas (2-8), is not resistant to the cases of extrapolation either. Furthermore, this way of estimation brings on unacceptable results in valuation cases of some objects whose market feature marks are equal to the lowest ones on the local market. On the other hand, it is worth mentioning that the final results of appraisals of medium objects ("not better than the best" and "not worse than the worst'), in reference to their comparative units, achieved by means of both methods are remarkably close. The divergence of estimations in variants A and C did not even exceed $17 \%$ of the estimated unit values. Realizing the potential faultiness of both methods of calculations we shall judge the result as very good. That means that the proposed mathematical model works very well in typical conditions of using the "in pairs comparison" method and can be, within conditions, a real and reliable alternative to it.

An advantage of the proposed alternative valuation model is its independence from market feature weight coefficients, almost always imposed a'priori in routine calculations, estimating of which sometimes can be very difficult and cause doubts about the accuracy of the final result of such a valuation. Testing of the correlation between the changes of market prices and marks of significant market features (at least expressed by numbers) is the immanent part of the method of least squares. We should also remark that the results of estimations given by the least squares method so well the estimations performed with "in pairs comparison" method, are based on all the market. This observation may suggest that the estimations using the method of least squares shall be more accurate. The proof of this hypothesis, however, must be a subject of another study.

\section{References}

[1] Hozer. J, Kokot S., Kuźmiński i in., Methods of statistical analysis in the pricing of real estates, Warsaw, Polish Federation of Valuers Associations, 2002. (in Polish).

[2] Rao C. R., Linear models in statistics, Warsaw, PWN, 1982 (in Polish).

[3] National Committee of Polish Federation of Valuers Associations, Use of the comparative approach in real estate valuation, Interpretative Note no. 1; 2008; (in Polish).

[4] National Committee of Polish Federation of Valuers Associations, Professional Standards of Valuers, Standard III. $7^{*}, 8^{\text {th }}$ edition , 2001 (in Polish).

[5] Law on real estates economy, Journal of Laws 2004 no 261, item 2603 (in Polish).

[6] Statutory Instrument Resolution of the Council of Ministers from 21st September, 2004 regarding the real estate valuation and preparing of valuation report (Journal of Laws no 207, item 2109) (in Polish). 